\title{
Comparison of Levobupivacaine and Clonidine with Bupivacaine and Clonidine in Spinal Anaesthesia for Lower Segment Caesarean Section
}

\author{
${ }^{1}$ Dr. Jyoti Kulkarni, ${ }^{2}$ Dr Veena Lodha, ${ }^{3}$ Dr Tushar Patil and ${ }^{4}$ Dr Ullhas Misal \\ 7, Bharat Nagar near Jyoti Mandir Shahnoorwadi Aurangabad Country: India
}

\begin{abstract}
Comparison Of Levobupivacaine And Clonidine With Bupivacaine And Clonidine In Spinal anaesthesia ForLowerSegmentCaesareanSection

Introduction: Intrathecal LevoBupivacaine is having similar clinical profile with less cardio-toxicity than Bupivacaine is used commonly for LSCS. Clonidine as an additive to LA provides effective, prolonged and dose dependent analgesia. In this study we compared effect of intrathecal Clonidine $30 \mu \mathrm{g}$ and $0.5 \%$ isobaric Levobupivacaine $9 \mathrm{mg}$ with Clonidine $30 \mu \mathrm{g}$ and 0.5\% hyperbaric Bupivacaine $9 \mathrm{mg}$ for LSCS. Material and method: In this study we want to compare onset, degree, maximum sensory level achieved, time required to achieve the maximum level of sensory blockade, duration of effective sensory blockade and onset and degree of effective motor blockade, its cardiac effect and effect on APGAR score of baby after intratheacal Clonidine $30 \mu \mathrm{g}$ as an adjuvant to intrathecal 0.5\% isobaric Levobupivacaine $9 \mathrm{mg}$ and 0.5\% hyperbaric Bupivacaine $9 m g$.

Observations:The mean time for the onset of motor blockade in patients in group B was $1.90 \pm 0.54$ min and in group $L$ was $2.15 \pm 0.47$ min. Mean time required for maximum motor blockade was $4.70 \pm 0.65$ min for group $B$ and $4.30 \pm 0.59$ min for group L. Time of onset of analgesia at T6 was $6.40 \pm 0.81$ in group B and $6.70 \pm 0.84$ min in L group. Time requited to achieve maximum level of analgesia was $7.20 \pm 1.21$ min in group $B$ and $7.33 \pm$ 1.26 min in group L. Bradycardia was statistically significant in patients of group B as compared to that in group $L$. Two dermatome regression in group $B$ was at $158.27 \pm 5.01$ min and in group $L$ it was at $157.83 \pm$ $3.49 \mathrm{~min}$. The first rescue analgesic required in group B was at $167.68 \pm 3.84$ min and in group $L$ was at 165.73 $\pm 4.65 \mathrm{~min}$.

Conclusion:We observed that that isobaric Levobupivacaine with Clonidine has got comparable pharmacokinetic in onset and offset of sensory and motor block, less cardiovascular side effects, good intraoperative and postoperative analgesia without sedation and adverse effect on Apgar score so we conclude that Levobupivacaine with Clonidine is a better choice in LSCS than Bupivacaine with Clonidine. Keywords:Levobupivacaine, Bupivacaine, Clonidine, LSCS
\end{abstract}

\section{Introduction}

Central neuraxial blockade is the most popular technique of anaesthesia for LSCS. It is having several advantages like economic,early onset, easy to perform and provides good quality of anesthesia ${ }^{1}$.Itdecreases blood loss, avoid risk of intubation and aspiration, provides early ambulation and early starting of breast feeding . Bupivacaine is most commonly used local anaesthetic drug for LSCS but cardio-toxicity is the limiting factor. Levobupivacainehaving similar clinical profile with less cardio-toxicitythan Bupivacaine is gaining popularity. ${ }^{1}$ It has demonstrated less affinity and strength of inhibitory effect on the inactivated state of cardiac sodium channels than the Bupivacaine and faster protein binding rate ${ }^{2}$.

To provide good quality of intra-operative anesthesia with post-operative analgesia different additives like Opioids, Ketamine, Midazolam, Neostigmine and $\alpha 2$ adrenergic agonist are used ${ }^{3}$. Opioids may cause pruritus, nausea, vomiting, urinary retention and respiratory depression either in mother and baby ${ }^{3}$. Neostigmine causes nausea, vomiting, bradycardia and hypotension. Midazolam causes neurotoxicity ${ }^{4}$.Clonidine is a selective partial $\alpha$-2adrenergic agonist provides effective, prolonged and dose dependent analgesia with a consequently decreased requirement of supplemental analgesics. ${ }^{5}$

This study was conducted in patients undergoing lower segment caesarean section to evaluate and compare the effect of Clonidine $30 \mu \mathrm{g}$ as an adjuvant to intrathecal $0.5 \%$ isobaric Levobupivacaine $9 \mathrm{mg}$ and $0.5 \%$ hyperbaric Bupivacaine $9 \mathrm{mg}$. Total volume of drug was $2 \mathrm{ml}$ in both the groups.

\section{Aims And Objectives}

In this study our primary aim was to compare onset, degree, maximum level achieved, time required to achieve the maximum level of sensory blockade, duration of effective sensory blockade and onset and degree of 
effective motor blockade after intratheacal Clonidine $30 \mu \mathrm{g}$ as an adjuvant to intrathecal $0.5 \%$ isobaric Levobupivacaine $9 \mathrm{mg}$ and $0.5 \%$ hyperbaric Bupivacaine $9 \mathrm{mg}$.

Our secondary aim was to compare effect of Clonidine $30 \mu \mathrm{g}$ as an adjuvant to intrathecal $0.5 \%$ isobaric Levobupivacaine $9 \mathrm{mg}$ and $0.5 \%$ hyperbaric Bupivacaine $9 \mathrm{mg}$. on vital parameters like pulse rate, mean arterial pressure, $\mathrm{SpO}_{2}$ respiratory rate intraoperative side effects like nausea, vomiting, bradycardia, hypotension, sedation, respiratory depression, dry mouth, effect on neonate (Apgar score) and time required for request of first rescue analgesic.

\section{Material And Method}

After approval from hospital ethics committee, detail clinical examination, investigations and written informed valid consent patients were posted for LSCS. Patients with ASA grade I and II, BMI $<35 \mathrm{~kg} / \mathrm{m}^{2}$ with age 18-35 yrs. posted for emergency or elective LSCS were included in this study. Patients were kept NBM for 6 hours prior to the elective procedure. On arrival in the operating room patients were preloaded with ringer lactate solution at $10 \mathrm{ml} / \mathrm{kg}$. Antiemetic prophylaxis was given using Injection Ondansetron $0.08 \mathrm{mg} / \mathrm{kg}$, Injection Ranitidine $1 \mathrm{mg} / \mathrm{kg}$ and Injection Metoclopramide $0.2 \mathrm{mg} / \mathrm{kg}$. Patients were randomized into two groups with 30 each, on the basis of sealed envelope technique.

Under all aseptic precautions Lumbar puncture was performed in L3-L4 interspace in left lateral position by using 23 gauge pencil point spinal needle. After obtaining clear and free flow of CSF Group B patients received injection hyperbaric $0.5 \%$ Bupivacaine $9 \mathrm{mg}$ and Clonidine $30 \mu \mathrm{g}$ and Group L patients received $9 \mathrm{mg}$ isobaric Levobupivacaine $0.5 \%$ and $30 \mu \mathrm{g}$ Clonidine intrathecally over 10 seconds with total volume $2 \mathrm{ml}$. Immediately supine position with wedge under right hip was given. Oxygen was administered through a face mask. Patient was monitored for pulse rate, mean arterial pressure, respiratory rate and sedation continuously. Hypotension defined as decrease in systolic pressure by more than $30 \%$ from baseline or decrease in mean arterial pressure more than 20\% was treated with bolus intravenous dose of Injection Ephedrine5-10 $\mathrm{mg}$ and intravenous fluids if required. Bradycardiadefined as heart rate less than 50/min was treated with IV Atropine $0.6 \mathrm{mg}$.

Sensory level was determined by pinprick using 24gauge hypodermic needle. Onset of analgesia was defined as time interval from completion of subarachnoid injection to the loss of pinprick sensation at T6. Maximum dermatomal level was tested by pinprick in mid-clavicularline, every minute until the level is stabilized for two consecutive tests. After that sensory level was tested every 15 minutes until two segment regression. Time taken to achieve maximum sensory level, two segment regression and time for first analgesic requiredwas noted.

Quality of analgesia was assessed by patients comfort and was graded as follows

I. Required general anaesthesia for completion of surgery

II. Pain that required addition of the analgesic drug.

III. Mild discomfort but did not required systemic analgesic.

IV. No discomfort at all during procedure

Onset of motor block was defined as the time from the injection of drug in subarachnoid space till the patient was unable to raise the extended legs. The degree of motor block was assessed with Bromage scale and graded as follows.

Grade

0 No motor block

1 Inability to raise extended legs

2 Inability to flex knee, able to flex the ankle

3 Complete motor block (Inability to flex the ankle )

Sedation was assessed by four point score and graded as follows:

0. Awake and alert

1. Mild sedation, easy to rouse

2. Moderate sedation, unable to remain awake

3. Difficult to arouse.

Incidence of side effects (nausea, vomiting, shivering, itching, pruritus, sedation, respiratory depression, bradycardia, dry mouth and hypotension) was recorded. Apgar score of baby at 1 and 5 minutes was recorded and graded as follows.

Sr. No.Sign 012

1 Respiratory efforts Absen Slow Irregula Good, crying

2Heart rate Absent Slow(below100) Over 100

3 Muscle tone Flaccid Flexion of extremitiesActive body movements

DOI: $10.9790 / 0853-1508019297 \quad$ www.iosrjournals.org

93 | Page 
4 Reflex irritability No Response Grimace Cry

5Colour Blue, Pale Body pink, extremities blue Complete pink

Total score: 10

No depression $\quad: 7-10$

Mild depression : : 4-6

Severe depression: $0-3$

Onset of postoperative pain was considered when patient requests first rescue analgesic.If patient complains of pain before delivery of baby injection Ketamine 0.5 to $1 \mathrm{mg} / \mathrm{kg}$ IV was given as analgesic. If pain persists after Ketamine then general anaesthesia was given.

For analysis of this data SPSS (statistical software for social sciences) version 20 was used. Data was presented in visual impression by using bar diagram. Analysis of data was performed using student's unpaired t-test for finding the significance of difference between means of two independent samples. Comparisons between two qualitative variables were performed with Pearson's chi-square test. P value $<0.05$ was considered to be statistically significant.

\section{Observations And Results}

This prospective study was carried out on sixty women with singleton pregnancy ASA grade I - grade II, undergoing caesarean section under spinal anaesthesia.There was no statistical significant difference among both the groups as far as age, height and weight were taken into consideration. Mean age in Group B was 22.83 \pm 2.61 yrs.while in Group $\mathrm{L}$ it was $23.3 \pm 3.26$ yrs. with $\mathrm{P}=0.543$. Mean height was Group B was $150.53 \pm$ $3.22 \mathrm{~cm}$ while in Group L it was148.76 \pm 4.79 with $\mathrm{P}=0.098$. Mean age was Group B was $60.20 \pm 4.97 \mathrm{~kg}$ while in Group $\mathrm{L}$ it was $62.30 \pm 4.42 \mathrm{~kg}$ with $\mathrm{P}=0.0 .089$.

The mean time for the onset of motor blockade in patients in group B was $1.90 \pm 0.54$ min and in group $\mathrm{L}$ was $2.15 \pm 0.47 \mathrm{~min}$ with $\mathrm{p}_{2} 0.087$. Itindicates that the differencewas statistically not significant. Mean time required for maximum motor blockade was $4.70 \pm 0.65$ min for group B and $4.30 \pm 0.59$ min for group L with $\mathrm{P}=0.056$. The difference between both the groups was statistically not significant.

Time required for loss of pinprick sensation at T6 was almost similar in both the groups. In group B $6.40 \pm 0.81$ and $6.70 \pm 0.84$ min for $\mathrm{L}$ group with $\mathrm{P}=0.164$ indicating that the difference between onset of analgesia was statistically not significant. Time requited to achieve maximum level of analgesia was $7.20 \pm$ $1.21 \mathrm{~min}$ in group $\mathrm{B}$ and $7.33 \pm 1.26 \mathrm{~min}$ in group $\mathrm{L}$ withP $=0.676$ indicting that time required to achieve maximum level was comparable in both groups. 27 patients in B group had analgesia (grade IV) whereas 3 patients had mild discomfort for which no analgesic was required (grade III). 26 patients in L group had sensory analgesia(grade IV) whereas 4 patients had mild discomfort for which no analgesic was required (grade III). None of the patients from both the groups required general anaesthesia. The difference between the two groups was statistically not significant.

We observed that after 15 minutes of block 3 patients in group Band 4 patients in group L were mildly sedated after 15 minutes while after 45 minutes 6 patients in group B and 5 patients in group L were moderately sedated.1 patient from each group was difficult to arouse. None had respiratory rate less than 12 and SPO2 less than 95\%. The difference between the two groups was statistically not significant. All babies have Apgar score $>9$ at 1 and 5 minutes. The difference between the two groups was statistically not significant.

Bradycardia was statistically significant in patients of group B as compared to that in group L.Basal mean arterial pressure was comparable in both the groups ( $p>0.05$ ). Hypotension was statistically significant in group B compared to group L.

The difference between the two groups was statistically not significant. Mean basal respiratory rate was $14.53 \pm 1.36$ per min in group B and $14.93 \pm 1.04$ per min in group L. The difference between the two groups was statistically not significant. Mean minimal respiratory rate was $13.10 \pm 1.12$ per min in group B and $13.47 \pm$ 1.4 per min in group L. The difference between the two groups was statistically not significant. Mean basal $\mathrm{SpO}_{2}$ Preoperative was $99.47 \pm 0.51 \%$ in the group B and $99.43 \pm 0.05$ in group L. Mean minimal intraoperative $\mathrm{SpO}_{2}$ was $99.23 \pm 0.73 \%$ in group $\mathrm{B}$ and $98.93 \pm 0.56 \%$ in group $\mathrm{L}$. Mean post-op $\mathrm{SpO}_{2}$ was $99.47 \pm 0.57 \%$ in $\mathrm{B}$ group and $99.53 \pm 0.51 \%$ in group $\mathrm{L}$. The difference between the two groups was statistically not significant.

Two dermatome regression in group B was at $158.27 \pm 5.01 \mathrm{~min}$ and in group $\mathrm{L}$ it was at $157.83 \pm 3.49$ $\mathrm{min}$. The difference between the two groups was statistically not significant. The first rescue analgesic required in group B was at $167.68 \pm 3.84 \mathrm{~min}$ and in group $\mathrm{L}$ was at $165.73 \pm 4.65 \mathrm{~min}$. The difference between the two groups was statistically not significant.

Incidence of vomiting was same in both the groups .2 patients had intraoperative vomiting and 1 had postoperative vomiting. 3 patients in group B and 2 patients in group $L$ had nausea intraoperatively .1 patient in each group had postoperative nausea. The difference between the two groups is statistically not significant. None of the patient had dry mouth or pruritus. 


\section{Discussion}

Spinal anesthesia is most preferred technique of anesthesia for LSCS. In pregnancy dose requirement of local anesthetic is decreased due to physiological changes in epidural space and reduction in CSF protein concentration. ${ }^{6,7}$ We can further decrease the dose by adding an adjuvant to local anaesthetic.Intrathecal Clonidine is safe in pregnant females as it isnot detected in the fetal circulation ${ }^{8}$.

Levobupivacaine is said to be less cardio-toxic and having more specific effects on sensory rather than motor nerve with shorter duration of analgesia and motor blockade. ${ }^{9,10,11}$ Misirlioglu K and etal and Feroz A. Dar etalcompared efficacy of intrathecal0.5\% levobupivacainewith $0.5 \%$ bupivacaine and fentanyl $25 \mu \mathrm{g}$ as an adjuvant. They noted that there was no significant difference in the quality of anesthesia and intraoperative side effectsbut time to complete regression of motor blockade was statistically lower in group L. ${ }^{12,13}$

Clonidine blocks the conduction of $\mathrm{C}$ and $\mathrm{A} \delta$ fibers and acts synergistically with localanaesthetics by its action of opening potassium channels. ${ }^{14}$ Intrathecal clonidine prolongs sensory as well as motor block of spinal anesthesia by activation of post synaptic $\alpha-2$ receptor in substantiageletinosa of spinal cord. ${ }^{15}$ It decreases local anesthetic requirements and provides prolonged postoperative analgesia. Also it acts as antiemetic , anxiolytic, reduces post spinal shivering and provides sedation without respiratory depression. ${ }^{15}$ Bupivacaine acts mainly by blockade of voltage gated $\mathrm{Na}+$ channel in the axonal membrane and presynaptic inhibition of calcium channels and a combination of these effects may explain the observed synergism between bupivacaine and clonidine. ${ }^{16,17,18}$

This decreased dose of LA Reduction in spinal anaesthesia can decrease incidence of maternal hypotension, high spinal block, and prolonged motor block. Due to good postoperative analgesia after cesarean section with intrathecal Clonidine, the mother is better able to take care of her newborn, which immediately improves mother-baby relationship, decreases prelacteal feeds (feeding any other substance before first breastfeeding). ${ }^{19}$ The suggested optimal dose of clonidine is $37.5 \mu \mathrm{g}$ for cesarean surgery, which allows reduction of up to $18 \%$ of the total dose of hyperbaric bupivacaine ${ }^{8}$.

In our study we observed that onset of analgesia was comparable in both groups. This indicate that Levobupivacaine and Bupivacaine are equipotent same findings were noted in different studies. ${ }^{20,12.21 .22,23,13,24}$ Gulen Guler ${ }^{22}$ et al reported longeronset of sensory blockade might be due to use of Fentanyl as an adjuvant. Maximum level of sensory blockade was upto T4-T6 dermatomeand time to reach maximum level was comparable in both groups same findings were observed by Aygen Turkmen ${ }^{25}$ et al. and Gulen Guler ${ }^{22}$ et al who used $10 \mathrm{mg}$ of LA with $15 \mu \mathrm{g}$ of Fentanyl. We noted that onset of motor blockade was comparable in both groupsSame findings were noted in previous studies by A.Mehta ${ }^{23}$ et al and Feroj Dar ${ }^{13}$ et al while Rashmi Duggal ${ }^{26}$ et al, Gulen Guler ${ }^{22}$ et al.

In our study sedation was not significant in both the groups. Sedation with Clonidine is due to central action produced due to hyper-polarisation of excitatory neurons localized in the nucleus coereleus ${ }^{57}$. Respiratory rate and $\mathrm{SpO}_{2}$ was well maintained. None of the patients in both the groups required treatment. Drowsiness was noted in $25 \%$ patients by Bhavini Bhushan ${ }^{28}$ et al who used $60 \mu \mathrm{g}$ Clonidine andAnjali Bhure ${ }^{29}$ et al observed increased incidence incidense of side effects like sedation, bradycardia, and dry mouth after $75 \mu$ g Clonidine indicating sedation is dose dependent.

In LSCSif mother is awake after delivery of baby, she is able to take care of her newborn which improves mother baby relationship, decreases prelacteal feeds, which has harmful effects ${ }^{29}$.

Mean Apgar score at $1 \mathrm{~min}$ and at $5 \mathrm{~min}$ was comparable in both groups. Our findings are same with that of Ranju singh ${ }^{30}$ et al, Nikhil Kothari ${ }^{20}$ et al,Bhavini Bhushan ${ }^{15}$ et aland Bajwa ${ }^{2}$ et al, InBupivacaine and Clonidine group.

Basal and maximal heart rate was comparable in both the groups. Statistically significant bradycardia was seen in Bupivacaine group.Our findings are similar to that of Rashmi Duggal ${ }^{26}$ et al and, Gulen Guler ${ }^{22}$ et al. while Ashok $\operatorname{Das}^{31}$ et al observed that that incidence of bradycardia was same in both the groups. Bradycardia could be due to baricity of Bupivacaine.Hyperbaric Bupivacaine is characterized by early onset of action, greater cephalic distribution causing high level of block and subsequent bradycardia and hypotension ${ }^{32}$.

Bradycardia in spinal anaesthesia is believed to result from blockade of sympathetic cardio accelerator (T1 to T4) fibres and decreased venous return to the heart. The decrease in preload is believed to be the most important cause of decrease in heart rate $^{8}$ Bupivacaine reduces the cardiac contractility by blocking the calcium transport. So higher sensory blockade and Bupivacaine's cardio depressant action might be responsible for bradycardia. Levobupivacaine has less cardiotoxicity due to less affinity and strength of inhibitory effect on cardiac sodium channels and faster protein binding rate ${ }^{2}$.

There was more fall in mean arterial pressure in group B (27\%) compared to group L (9\%).Our observations are similar to of Rashmi Duggal ${ }^{26}$ et al, Ashok Das ${ }^{31}$ et al and Richa Chandra ${ }^{27}$ et al , while Mantouvalou $^{33}$ et al observed higher incidence of hypotension (42.5\% in group B and $17.5 \%$ in group L). might be due to use of higher dose of LA $15 \mathrm{mg}$ compared to $9 \mathrm{mg}$ in our study. 
Two dermatome regression in both the groups were comparable. WhileP.Gautier et $\mathrm{al}^{34}$, RashmiDuggal et $\mathrm{al}^{26}$ andGulen Guler ${ }^{22}$ et al. P.Gautier ${ }^{34}$ used LA with Sufentanil and Gulen Guler ${ }^{22}$ et al used LA with $15 \mu \mathrm{g}$ of Fentanyl found that 2 dermatome regression was shorter. This shows that addition of Clonidine increases time to two dermatome regression.

First rescue analgesic wasneeded at $167.68 \pm 3.84 \mathrm{~min}$ in group Band in group L it was needed at $165.73 \pm 4.65 \mathrm{~min}$. Our findings are similar with that of Bajwa ${ }^{2}$ etal while Rashmi Dugga ${ }^{26}$ et al observed earlier requirement of rescue analgesic (in B group it was at $103.47 \pm 10.18 \mathrm{~min}$ and in L group it was at $80.03 \pm$ $8.12 \mathrm{~min}$ ) with fentanyl as an additive indicates that Clonidine as an adjuvant provides prolonged postoperative analgesia than other additives.

Incidence of vomiting was same in both the groups. 1 patient in each group had postoperative nausea. None of the patient had dry mouth or pruritus.

From all our observation we can conclude thatintrathecalisobaric Levobupivacaine with Clonidine is better alternative to Bupivavacaine for LSCS as it provides good quality of sensory and motor blockade, better cardiac stability without sedation in mother and any effect on baby.

\section{Conclusion}

We observed that that isobaric Levobupivacaine has got comparable pharmacokinetic in onset and offset of sensory and motor block, less cardiovascular side effects and comparable postoperative analgesia to hyperbaric Bupivacaine, so we conclude that Levobupivacaine with Clonidine is a better choice in LSCS than Bupivacaine with Clonidine.

It provides good quality of intraoperative and prolonged postoperative analgesia with reduced dose of LA ( $9 \mathrm{mg}$ ) and without sedation and adverse effect on Apgar score of baby. Drawback of our study is that we compared hyperbaric Bupivacaine with isobaric Levobupivacaine as hyperbaric Levobupivacaine preparation is not available in the market. So it needs to be further investigated.

\section{Biliography}

[1]. Miller RD, Eriksson LI, Fleisher LA, Wiener-Kronish JP, Young WL; Anaesthesia for Obstetrics. In Miller's Anaesthesia, 7th edition, Chapter 69, Saunders; 2009.

[2]. Bajwa s s, Kaur J, Clinical profile of Levobupivacaine in regional anaesthesia: A systematic review. J Anesthesiology clin pharmac01 2013;29:530-9

[3]. Saxena AK, Arava SE., Current concepts in neuraxial administration of opioids and nonopioids: An overview and future perspectives. Indian J Anaesth 2004;48:1324

[4]. U Bakshi, S Chatterjee.SSengupta, D Gupta, .Adjuvant drugs in central neuraxial analgesia-A Review. The Internet Journal of Anesthesiology.2009 volume 26 Number1.

[5]. Chiari A, Lober C, Eisenach JC, Wildling E, Krenn C, Zavrsky A, et al. Analgesicand hemodynamic effects of intrathecal Clonidine as a sole analgesic agent during First stage of labor: A dose response study Anesthesiology 1999;91:3889

[6]. SharmaK,Batra YK, Singh H, Effect of decreased cerebrospinal fluid proteins on the spread of local anaesthetic drugs in pregnancy. Indian J Med Res.1990 jun ;92:175-7

[7]. H Saxena,SSingh,SGhildiyal, Low dose intrathecal Clonidine with Bupivacaine improves onset and duration of block with haemodynamic instability.Ispub.com/IJA/ volume 23/1/9137

[8]. SukhminderJit Singh Bajwa, SukhwinderKaur Bajwa,1 JasbirKaur, Amarjit Singh, Anita Singh,1 and Surjit Singh Parmar. Prevention of hypotension and prolongation of postoperative analgesia in emergency cesarean sections: A randomized study with intrathecal Clonidine. Int J CritIllnInj Sci. 2012 May-Aug; 2(2): $63-69$

[9]. P. Gautier1, M. De Kock2*, L. Huberty1, T. Demir1, M. Izydorczic1 and B. VandericComparison of the effects of intrathecalropivacaine, levobupivacaine, and bupivacaine for Caesarean sectionkBritish Journal of Anaesthesia 91 (5): $684 \pm 9$ (2003) DOI: 10.1093/bja/aeg251

[10]. Camorcia M, Capogna G, BerittaC, Columb MO. relative potencies for motor block after intrathecalropivacaine, levobupivavacaine, and bupivacaine. AnesthAnalg2007;104:904-907

[11]. Cynthia A WongAdvances in laboranalgesiaInternational Journal of Women's Health 2009:1 139-154

[12]. Misirlioglu K1, Sivrikaya GU2, Hanci A3, Yalcinkaya A3 Intrathecal low-dose levobupivacaine and bupivacaine combined with fentanylin a randomised controlled study for caesarean section: blockade characteristics, maternal and neonatal effectsHIPPOKRATIA 2013, 17, 3: 262-267

[13]. Feroz A. Dar, Ishrat H. Mir, Hilal A. Bhat Comparison of intrathecal hyperbaric Bupivacaine and Levobupivacaine for Cesarean section Ain shams Journal of Anesthesiology 2015,08:89-92

[14]. Wei ZY, Karim F, Roerig SC. Spinal morphine/Clonidine antinociceptive synergism: involvement of G proteins and N-type voltage-dependent calcium channels. J PharmacolExpTher 1996; 278:1392-407.

[15]. Shah BB, Joshi SS, Shidhaye RV, Lakhe JN. Comparison of different doses of Clonidine as an adjuvant to intrathecal Bupivacaine for spinal anesthesia and postoperative analgesia in patients undergoing caesarean section. Anaesth Pain \& Intensive Care 2012;16(3):266-272

[16]. OlfaKaabachi O, Zarghouni, et al. Clonidine 1 microgram/kg is safe and effective adjuvant to to plain Bupivcaine in spinal anaesthesia in adolescent. AnesthAnalg. 2007; 105:516-519.)

[17]. B.S.Sethi1, Mary Samuel2, Deepak Sreevastava3 Efficacy of Analgesic Effects of Low Dose Intrathecal Clonidine as Adjuvant to Bupivacaine Indian Journal of Anaesthesia 2007; 51 (5) : 415-419

[18]. Zahoor Ahmad Shah1, Raksha Kundal2, *Arun Kumar Gupta3, MohdSadiq Malla4, Faisal Zahoor5, Vijay Kundal6 Sameena Ashraf Kirmani7, ShiguftaQazi Efficacy of analgesic effect of low dose intrathecal clonidine as adjuvant tobupivacaine in urogenital surgeries: study in a Kashmiri population 
[19]. Hala M. Goma, Juan C. Flores-Carrillo and VíctorWhizar-Lugo http://dx.doi.org/10.5772/58851Chapter 4 ;Spinal Additives in Subarachnoid Anaesthesia for Cesarean Sectionhttp://dx.doi.org/10.5772/58851page 68-95.

[20]. Nikhil Kothari, JaishriBogra, Ajay K Chaudhary. Evaluation of analgesic effects of intrathecal Clonidine along with Bupivacaine in cesarean section. Year : 2011 Volume : 5 Issue : 1 Page : 31-35

[21]. Sunil B. V, Jajee P. R. "Intrathecal Clonidine as an Adjuvant with Hyperbaric Bupivacaine for Caesarean Section". Journal of Evolution of Medical and Dental Sciences 2014; Vol. 3, Issue 25, June 23; Page: 6993-7001, DOI: 10.14260/jemds/2014/2850

[22]. Guler G, Cakir G, Ulgey A, Ugur F, Bicer C, Gunes I, Boyaci A. A comparison of spinal anesthesia with Levobupivacaine and hyperbaric bupivacaine for caesarean sections: a randomized trial open. J Anesthesiol, 2012; 2:84-89.

[23]. Mehta, A., Gupta, V., Wakhloo, R., Gupta, N., Gupta, A., Bakshi, R., et al. 2007. Comparative evaluation of intrathecal administration of newer local anaesthetic agents Ropivacaine and Levobupivacaine with Bupivacaine in patients undergoing lower limb surgery. Internet J Anesthesiol., 17: 17

[24]. P. Gautier, M. De Kock, L. Huberty, T. Demir, M. Izy- dorczic and B. Vanderick, "Comparison of the Effects of İntrathecalRopivacaine, Levobupivacaine and Bupiva- caine for Caesarean Section,” British Journal of Anaesthesia, Vol. 91, No. 5, 2003, pp. 684-689. doi:10.1093/bja/aeg251

[25]. Turkmen A, Moralar DG, Ali A, Altan A; Comparison of the anesthetic effects of intrathecalLevobupivacaine + Fentanyl and Bupivacaine + Fentanyl during caesarean section. Middle East J Anesthesiol., 2012; 21(4): 577-582.

[26]. RashmiDuggal, RuchiKapoor, GajendraMoyal, a Comparison of intrathecalLevobupivacaine with hyperbaric Bupivacaine for elective caesarean section: A Prospective randomized double blind study, J obset. anes cri care 2015;5 : 78-83.

[27]. Richa Chandra, Harjeetsingh Nanda, Abhishek Kumar, Comparison of intrathecalLevobupivacaine versus Bupivacaine with Clonidine as adjuvant.international Journal of scientific study,octo 2014,vol 2.issue 7

[28]. Shah BB, Joshi SS, Shidhaye RV, Lakhe JN. Comparison of different doses of Clonidine as an adjuvant to intrathecal Bupivacaine for spinal anesthesia and postoperative analgesia in patients undergoing caesarean section. Anaesth Pain \& Intensive Care 2012;16(3):266-272

[29]. Bhure A, Kalita N, Ingley P, Gadkari CP. Comparison of different doses of Clonidine as an adjuvant to intrathecal Bupivacaine for spinal anesthesia and postoperative an-algesia in patients undergoing caesarian section. People's Journal of Scientific Research2012; 5:19-23.

[30]. Singh R, Gupta D, Jain A. The effect of addition of intrathecal Clonidine to hyperbaric Bupivacaine on post-operative pain after caesarean section: a randomized control trial. Saudi $j$ anaesth.2013;7:283-90

[31]. Dr. Ashok Das*, Dr. RajdipHazra,Dr. BivashHalder, Dr. SusmitaGhosh, Dr. SisirChakraborty, comparison of the effects of intrathecal Bupivacaine, Levobupivacaine and Ropivacaine in lower abdominal surgery: a double-blind, randomized controlled trial using isobaric preparations International Journal of Information Research and Review Vol. 2, Issue, 04, pp. 636-641, April, 2

[32]. HalaM.Goma, Juan C Spinal additives in subarachnoid anaesthesia for caesarean section http://dx.doi.org/10.5772/58851

[33]. Mantouvalou, M., Ralli, S., Arnaoutoglou, H., Tziris, G. and Papadopoulos, G. 2008 . Spinal anesthesia: Comparison of plain Ropivacaine, Bupivacaine and Levobupivacaine for lower abdominal surgery. ActaAnaesth., 59: 65-71

[34]. W.P. Gautier, M. De Kock, L. Huberty, T. Demir, M. Izy- dorczic and B. Vanderick, "Comparison of the Effects of İntrathecalRopivacaine, Levobupivacaine and Bupiva- caine for Caesarean Section,” British Journal of Anaesthesia, Vol. 91, No. 5, 2003, pp. 684-689. doi:10.1093/bja/aeg251 